\section{PSYCHOLOGICAL EFFECTS}

\section{OF DISASTERS}

ing types of injuries: 2,007 had different types of impairment of the locomotor system; 653 had closed fractures; 286 had open fractures; 377 received treatment for crush syndrome; 56 received amputations; and seven had double amputations.

Methods: To help the injured children, a two-step assistance process was organized: 1) prehospital; and 2) specialized care.

Results: The best results were achieved when the specialized medical care was provided close to the location of the disaster. The general results proved to be better when children were concentrated in specialized hospitals where they were treated by pediatricians of various specialties.

Conclusions: At present, medical help to children with trauma consequences is a problem due to the blockade of the Republic and acute lack of medical supplies and materials.

\section{5}

\section{Post-Traumatic Stress Disorder after Impending Threat}

Lundin T
Mass emergencies and disasters regularly will lead to an overwhelming threat. The somatically injured and those who have escaped uninjured, have experienced a real or existential threat to their lives, well-being, or future health.

Most disaster victims have been assumed to cope well with this situation. However, follow-up studies of disaster-affected persons over the last two decades have revealed a high percentage with post-traumatic stress disorders (PTSD).

The etiology and symptomatology of this disaster-specific mental disorder will be presented, as well as a brief review of some recent studies. Guidelines for secondary prevention (crisis intervention) and treatment of the post-traumatic stress syndrome resulting from a disaster situation will be discussed.

\section{6}

\author{
Psychological Stresses in Disaster Care \\ Workers and Emergency Personnel \\ Doyle $C J$, * Maino $J^{* *}$ \\ * University of Michigan \\ ** Foote Hospital \\ Ann Arbor, Michigan, USA
}

Psychological stress is well-known to occur in victims of disasters. Attention to psychological triage and care for victims and families has become routine. More information has come to light in recent years that disaster care workers and even emergency personnel who experience difficult or extremely traumatic cases have difficulty coping with the psychological stress.

This presentation examines several methods of modifying that stressful experience, or treating the emotional stress that ensues, and hopefully to prevent Post-Traumatic Stress syndromes and disorders. Formal Critical Incident Stress Debriefing (CISD) teams are used in many locations when an especially difficult experience for emergency care workers has occurred, or after a disaster. These teams provide venting and debriefing for emergency care workers within peer groups, and add separate sessions for casualties and family if necessary. Other methods that can aid stress in disaster care workers are defusing "stress hardening" and the practice of good physical and emotional health. 